
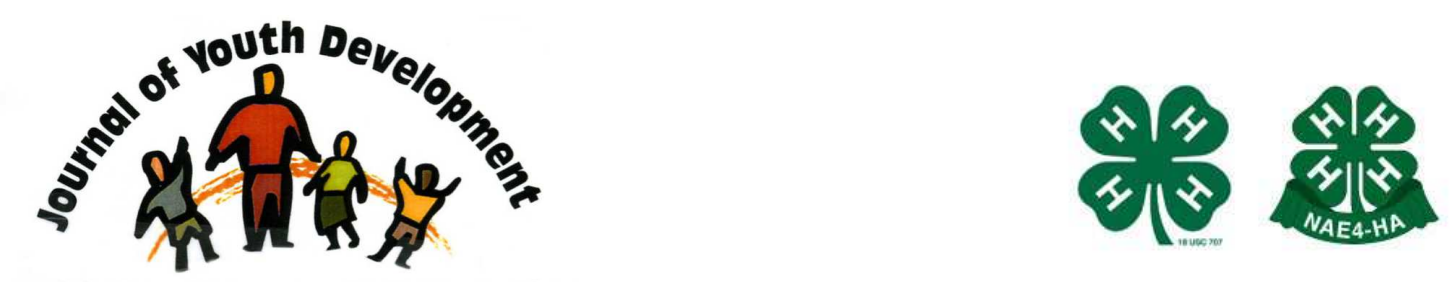

Bridging Research \& Practice

\title{
Defining Effective Programs: How to Navigate Through the Diverse Definitions
}

\author{
Brian Brandt \\ College of Ag, Human\& Natural Resource Sciences \\ Washington State University, Pierce County Extension 4-H \\ Pullman, WA \\ bbrandt@wsu.edu
}




\title{
JOURNAL OF YOUTH DEVELOPMENT \\ bridging research and practice

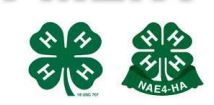

Volume 7, Number 4, Winter 2012

Article 120704RR001

\section{Defining Effective Programs: How to Navigate Through the Diverse Definitions}

\author{
Brian Brandt \\ Washington State University, Pierce County Extension 4-H
}

\begin{abstract}
There are many organizations that use shared terms to describe effective programs but don't agree on the definition of these terms. Terms such as evidence based, research-based, proven practices, and promising practices have multiple definitions amongst practitioners. Exploring the different definitions of these shared terms, by yourself or with your peers, is one way to discover how programs are defined by others. This article and links will lead you through a process to understand the variety of youth development definitions used by practitioners and challenge you to create common definitions that will lead to better discussions with others regarding the effectiveness of programs.
\end{abstract}

\section{Introduction}

Many stakeholders want assurance that they are supporting effective programs. There are currently many labels, which various groups use to describe effectiveness. Some labels, such as, "Evidence Based Practice" (EBP) or "evidence based program," are used to get funding for many programs. Programs labeled as "evidence based" are being selected more frequently by agencies, funders, politicians, and government agencies that want to select the most effective programs for support and implementation (Embry \& Biglan 2008; McCall, 2009; Slavin, 2008; Strode, et al., 2003; Williams-Taylor, 2007). Since there are no commonly agreed upon definitions, practitioners need to be well versed in different groups' definitions and their own personal definitions. After acquiring a stronger understanding professionals will have improved communication and reduced misunderstandings. Professionals will be better able to clarify to funders, stakeholders, and other agencies what definition they use to describe the effectiveness of their program. If your program does not meet one group's definition of "evidence based", you will be able to use other terms that describe your programs effectiveness.

In order to assist you with building your programs, the following worksheet was developed. The team may work to create common answers to some of the questions in the "Exploring your New Understanding" section. Or, a team may use this as a staff development option by splitting up 
the research section and reporting back what individuals learned. This worksheet will take about 20-30 minutes. You must be connected to the internet to complete the research section.

This interactive internet guide will help you:

1. have a better understanding of the diversity of terms used to describe effective programs and practices;

2. understand others' definitions of terms such as, evidence based program, evidence based practice, science based practices, research based, proven practices, promising practices, or others;

3. explain how your program is defined by yourself and others;

4. to be able to have better networking and collaboration discussions;

5. engage in the material through research and writing;

6. increase your engagement in the material;

7. increase reflection on learning;

8. prepare to apply your learning in future stakeholder discussions and networking.

Write your definitions below before reading further.

Evidence based program:

Evidence based practice:

Science based practice:

Research based:

Proven practice:

Promising practice: 
Youth professionals work and collaborate in many professional fields such as schools, afterschool programs, drug and alcohol treatment facilities, juvenile justice centers, violence prevention programs and social work programs. When youth professionals are collaborating, they use many terms to describe why their programs are effective. They use terms such as: evidence based program, evidence based practice, science based practice, research based, proven practices and promising practices. Currently, many different terms are used. Even when the same term, "evidence based," is used within a field, there is no agreed upon definition of what the term means (Slavin, 2008). In February 2011, definition searches using MerriamWebster's on-line dictionary and the Cambridge on-line dictionary all produced no results when searching for "evidence based." Dictionary.com produced only a medical field specific definition.

This lack of consistency has consequences, "...there is no consensus regarding the definition and what criterion makes a program evidence based. This of course leads us to the problem of miscommunication" (Williams-Taylor, 2007). The miscommunication around different definitions can impede networking and collaboration building. Without good networks and collaboration, it can negatively impact the youth we serve. A solution is to have a general understanding of others' definitions and some additional terms that are used to describe effective programs. Youth professionals can then have a clear, articulate discussion with each other and work on stronger networking and collaboration.

\section{History}

Evidence based practices originated in the medical field and have only been around the last 60 years (Williams-Taylor, 2007). In 1972, Archie Cochrane published Effectiveness and Efficiency: Random Reflections on Health Services, in which he criticized the medical establishment for not basing decisions on sound research and advocated for strong research to drive practice in health services. The medical field has since seen many improvements and lives saved as a result of adopting evidence based practices (Williams-Taylor, 2007). "The fields of medicine and welfare policy show that practice guided by rigor and evidence can produce remarkable advances" (Whitehurst, 2003).

\section{Attempt to Have a Common Definition}

There are many different definitions of "evidence based" within the varied professions that work with youth. However, there is a growing movement to define and clarify evidence based programs among these different professions, agencies, funders and politicians (McCall, 2009). One attempt at a general definition is, "A practice is defined as a habitual or customary performance or operation action or something that a professional does in order to achieve a positive outcome" (Salvin, 2008). Another is, "In its simplest and most direct form, evidence based practice often consists of identifying service programs that have been evaluated and found effective in one location and replicated those service programs in another" (McCall, 2009). 


\section{Your Learning}

Your task is to follow the links below and learn more about the definitions. The groups were selected because during the literature search, they were cited frequently and by many authors. These are not intended to be taken as a complete list, but do contain enough diversity for your learning. How much time you spend is up to you. Spend as much time as you need to have a stronger understanding of the differences and similarities of the definitions of evidence based. As you do your research, notice that some sites use of levels to rank programs. Some add additional labels, such as science based practice, research based, proven practice, and promising practice to describe effective programs. Some use the term "strong" to define the evidence used and indicate that a program is effective. You also will discover guides on how to select programs, based on that group's definition, which may be helpful in future decisions. After you finish your research, you will be asked to create your new definitions of evidence based program, evidence based practice, science based practice, research based proven practice, and promising practice.

\section{Your Turn Investigating}

For each of the following groups, you will find a description, link and some questions. Discuss and answer the questions in the box below each section.

\section{Best Evidence Encyclopedia}

"The Best Evidence Encyclopedia is a free web site created by the Johns Hopkins University School of Education's Center for Data-Driven Reform in Education (CDDRE) under funding from the Institute of Education Sciences, U.S. Department of Education. It is intended to give educators and researchers fair and useful information about the strength of the evidence supporting a variety of programs available for students in grades $\mathrm{K}-12$. The Best Evidence Encyclopedia provides summaries of scientific reviews produced by many authors and organizations, as well as links to the full texts of each review." (http://www.bestevidence.org/aboutBEE.htm, September 6, 2012).

Review the criteria at http://www. bestevidence.org/aboutBEE.htm What stands out to you in their definition and/or criteria? Likes? Dislikes? What works/or doesn't work well with your current partnerships and collaborations?

Notes:

\footnotetext{
What Works Clearinghouse Institute of Education Sciences

"Our goal is to provide educators with the information they need to make evidence-based decisions. We do this through a systematic review process which applies rigorous research standards to identify high-quality research and summarize its findings." (http://ies.ed.gov/ncee/wwc/ReviewProcess.aspx, September 6, 2012).

Review the criteria at http://ies.ed.gov/ncee/wwc/findwhatworks.aspx What stands out to you in their definition and/or criteria? Likes? Dislikes? What works/or doesn't work well with your current partnerships and collaborations?
} 
Notes:

\section{Promising Practices Network}

"The Promising Practices Network (PPN) is a group of individuals and organizations who are dedicated to providing quality evidence-based information about what works to improve the lives of children, families, and communities." (http://www.promisingpractices.net/about ppn.asp, September 6, 2012)

Review the criteria at http://www.promisingpractices.net/programs.asp What stands out to you in their definition and/or criteria? Likes? Dislikes? What works/or doesn't work well with your current partnerships and collaborations?

Notes:

\section{SAMHSA: Substance Abuse Mental Health Services Administration National Registry of Evidence-based Program and Practices \\ "The Substance Abuse and Mental Health Services Administration's (SAMHSA) mission is to reduce the impact of substance abuse and mental illness on America's communities." (http://www.samhsa.gov/about, September 6, 2012).}

Review the criteria at http://www.nrepp.samhsa.gov/Search.aspx What stands out to you in their definition and/or criteria? Likes? Dislikes? What works/or doesn't work well with your current partnerships and collaborations?

Notes:

\section{Office of Juvenile Justice and Delinquency Prevention (OJJDP)}

"OJJDP, a component of the Office of Justice Programs, U.S. Department of Justice, accomplishes its mission by supporting states, local communities, and tribal jurisdictions in their efforts to develop and implement effective programs for juveniles. The Office strives to strengthen the juvenile justice system's efforts to protect public safety, hold offenders accountable, and provide services that address the needs of youth and their families." (http://www.ojjdp.gov/about/about.html. September 6, 2012) 
Review the criteria at http://www.ojjdp.gov/mpg/search.aspx

What stands out to you in their definition and/or criteria? Likes? Dislikes?

What works/or doesn't work well with your current partnerships and collaborations?

Notes:

\section{Blue Prints for Violence Prevention}

"In an effort to establish more complete and valuable information to impact violence-related policies, programs, and practices, CSPV works from a multi-disciplinary platform on the subject of violence and facilitates the building of bridges between the research community and the practitioners and policy makers." ( http://www.colorado.edu/cspv/aboutus/index.html, September 6, 2012)

Review the criteria at http://ibs.colorado.edu/cspv/blueprintsquery/ What stands out to you in their definition and/or criteria? Likes? Dislikes? What works/or doesn't work well with your current partnerships and collaborations?

Notes:

\section{Access Center Research Continuum}

"The mission of the Access Center is to provide technical assistance that strengthens State and local capacity to help students with disabilities effectively learn in the general education curriculum." (http://www.k8accesscenter.org/index.php/about/, September 6, 2012)

Review the criteria at (http://www.k8accesscenter.org/training resources/reasearchapproach.asp) What stands out to you in their definition and/or criteria? Likes? Dislikes? What works/or doesn't work well with your current partnerships and collaborations?

Notes:

\section{Coalition for Evidence-Based Policy}

"A nonprofit, nonpartisan organization, the Coalition seeks to increase government effectiveness through the use of rigorous evidence about what works....The Coalition 
advocates many types of research to identify the most promising social interventions." (http://coalition4evidence.org/wordpress/?page id=6, September 6, 2012)

Review the criteria at http://coalition4evidence.org/wordpress/?page id=1488 What stands out to you in their definition and/or criteria? Likes? Dislikes? What works/or doesn't work well with your current partnerships and collaborations?

Notes:

\section{Child Trends}

"Child Trends is a nonprofit, nonpartisan research center that studies children at all stages of development. We seek to improve the lives of children and youth by conducting high-quality research and sharing it with the people and institutions whose decisions and actions affect children." (http://childtrends.org/ catdisp page.cfm?LID=124, September 6, 2012)

Review the criteria at http://childtrends.org/ catdisp page.cfm?LID=CD56B3D7-2F05-4F8EBCC99B05A4CAEA04 )

What stands out to you in their definition and/or criteria? Likes? Dislikes?

What works/or doesn't work well with your current partnerships and collaborations?

Notes:

\section{Internet Search by Key Words Option}

You may also just do an internet search by searching any of the terms and your field. Example: "'Evidence Based Programs' and "[insert your professional field]."

Group:

Internet Address:

What stands out to you in their definition and/or criteria? Likes? Dislikes?

What works/or doesn't work well with your current partnerships and collaborations?

Notes: 


\section{Exploring Your New Understanding}

Upon completion of your research, these next steps are designed to guide you through a process that solidifies your understanding of youth development terminology. After completing the sheet, you will be able to have clearer and more in-depth discussions with your peers and collaborators.

Step One: Write your definition of the terms below. Has it changed from your definitions above?

Evidence based program:

Evidence based practice:

Science based practice:

Research based:

Proven practice:

Promising practice:

Step Two: What are good ways to have discussions around EBP with other professionals? (Example: You used evidence basis in your discussion/presentation. Understanding that there are many different definitions, what is yours? Is it connected to any organization's definition? 
Step Three:

Is there a group with which you align your practice?

Step Four:

Are you engaged in any collaborations or partnerships that it would be advantageous to have a discussion clarifying the definitions used?

Step Five:

Select a current program for which you are seeking funding or stakeholder support. How would you describe it? What definition would you use and by what group?

\section{Summary}

The purpose of your exploring this topic and the writing activities is to support your understanding of the issues around the language we use to talk about effective programs. In summary you should now have a better understanding of:

1. the diversity of terms used to describe effective programs and practices;

2. others' definitions of terms such as evidence based program, evidence based practice, science based practices, research based, proven practices, promising practices, or others;

3. how your program is defined by yourself and others;

4. the importance of having the same definition when discussing networking and collaboration discussions around effective programs. 


\section{References}

Cochrane, A. (1972). Effectiveness and Efficiency. Random Reflections on Health Services. Nuffield Provincial Hospitals Trust.

Embry D.D., \& Biglan A. (2008). Evidence-based kernels: fundamental units of behavioral influence. Clinical Child Family Psychology. 11:77-113.

McCall, R.B. (2009). Evidence-based programming in the context of practice and policy. SRCD Social Policy Report, 23 (No. 3). 3-18.

Slavin, R.E. (2008). What works? Issues in synthesizing educational program evaluations. Educational Researcher, 37 (1), 5-14.

Strode, A., Aisenberg, G., Behan, K., Blodgett, C., Botzer, M., Brave Heart, S., et al. (2003). "Resource Guide and Literature Review for Best and Promising Mental Health Practices." The Washington Institute for Mental IIIness Research and Training. Washington State University Spokane. 1-294.

Whitehurst, G.J. (2003). Identifying and implementing educational practices supported by rigorous evidence: A user-friendly guide. Washington, D C.: U.S. Department of Education, Institute of Education Sciences, National Center for Education Evaluation and Regional Assistance. Retrieved February, 2012. On-line:

http://www.ed.gov/rschstat/research/pubs/rigorousevid/rigorousevid.pdf

Williams-Taylor, L. (2007). Research Review Evidence Based Programs and Practice: What Does it All Mean? Children's Services Council of Palm Beach County. Research-to-Results Brief. Washington, DC: Child Trends.

(C) Copyright of Journal of Youth Development Bridging Research and Practice. Content may not be copied or emailed to multiple sites or posted to a listserv without copyright holder's express written 
permission. Contact Editor at: patricia.dawson@oregonstate.edu for details. However, users may print, download or email articles for individual use.

ISSN 2325-4009 (Print); ISSN 2325-4017 (Online) 